\title{
Caracterização da forragem e da extrusa de clones de capim elefante anão sob lotação intermitente
}

\section{Characterization of forage and extrusa clones dwarf elephant grass under rotational stocking}

\author{
Tatiana Pires Pereira ${ }^{1 *}$; Elisa Cristina Modesto²; Ludmila Lacerda Campana ${ }^{3}$; \\ Carlos Augusto de Miranda Gomide ${ }^{4}$; Domingos Sávio Campos Paciullo"; \\ Delci de Deus Nepomuceno ${ }^{5}$; Carlos Augusto Brandão de Carvalho ${ }^{2}$; \\ Mirton José Frota Morenz ${ }^{4}$; João Carlos de Carvalho Almeida ${ }^{2}$
}

\begin{abstract}
Resumo
Este trabalho foi realizado com o objetivo de avaliar o comportamento ingestivo de novilhas mestiças e as características químicas da forragem de dois clones de capim-elefante anão ('BRS Kurumi' e CNPGL 00-1-3) submetidos a diferentes estratégias de manejo por meio de métodos de amostragem da forragem (planta inteira, extrusa e simulação manual de pastejo. O experimento foi conduzido na Embrapa Gado de Leite, em Coronel Pacheco, MG.). Utilizou-se o delineamento inteiramente casualizado, num esquema fatorial $(2 \times 2 \times 2)$, com três repetições cada. Os tratamentos consistiram dois clones de capim-elefante ('BRS Kurumi' e CNPGL 00-3-1), duas interceptações luminosas (IL) na entrada dos animais (90 e $95 \%$ ) e duas alturas de resíduo pós-pastejo (30 e $50 \mathrm{~cm}$ ), com três repetições. As análises bromatológicas demonstraram que a metodologia da simulação manual de pastejo possibilita uma estimativa aceitável da forragem selecionada pelos animais em pastejo e a amostragem de planta inteira não representa a dieta selecionada pelo animal. Para a colheita de extrusa foi feita avaliação da taxa e massa do bocado, frações da planta e composição química da forragem ingerida. As características, estruturais e valor nutritivo do clone 'BRS Kurumi' facilitou maior aporte de forragem pelo animal, o que sugere seu uso em sistema de pastejo.
\end{abstract}

Palavras-chave: Bocado, extrusa esofágica, interceptação luminosa, valor nutritivo

\footnotetext{
Abstract

The objective of this trial was to evaluate the behavior ingestive of crossbred heifers and chemical characteristics of the material from two clones of dwarf elephant grass (BRS Kurumi 'and CNPGL 01/03/00) submitted to different management strategies through sampling of forage (whole plant extrusa and manual hand plucking. The experiment was conducted at Embrapa Dairy Cattle, Coronel Pacheco, MG. We used a completely randomized design with factorial $(2 \times 2 \times 2)$ with three replications. The

${ }^{1}$ Discente do Curso de Doutorado do Programa de Pós-Graduação em Zootecnia, Universidade Federal Rural do Rio de Janeiro, UFRRJ, Seropédica, RJ. E-mail: tpireszootec@gmail.com

${ }^{2}$ Profs., Instituto de Zootecnia, UFRRJ, Seropédica, RJ. E-mail: ecmodesto@gmail.com; carloscarvalho_ufrrj@yahoo.com.br; jcarvalho@ufrrj.br

${ }_{3}^{3}$ Discente do Curso de Mestrado do Programa de Pós-Graduação em Zootecnia, UFRRJ, Seropédica, RJ. E-mail: ludbio@yahoo. com.br

${ }^{4}$ Pesquisadores, Empresa Brasileira de Pesquisa Agropecuária, EMBRAPA, Juiz de Fora, MG. E-mail: cagomide@cnpgl.embrapa. br; domingos@cnpgl.embrapa.br; mirton.morenz@hotmail.com

${ }^{5}$ Médico Veterinário Autônomo, Dr. em Ciência Animal e Pastagem, ESALQ, SP. E-mail: delci_ufrrj@yahoo.com.br

* Autor para correspondência
} 
treatments consisted of two clones of elephant grass (BRS Kurumi 'and CNPGL 01/03/00), two light interception at the entrance of the animals ( 90 and 95\%) and two heights of post-grazing residue ( 30 and $50 \mathrm{~cm}$ ) with three replications. The chemical analysis showed that the methodology manual grazing simulation enables an acceptable estimate of the forage selected by grazing animals and the sampling of the whole plant is not selected by the animal diet. To harvest extrusa rate evaluation and mass bit, fractions and chemical composition of the plant of the ingested material was taken. Characteristics, structural and nutritional value of clone BRS 'Kurumi' facilitated greater forage intake by the animal, suggesting its use in grazing systems.

Key words: Bit, light interception, esophageal extrusa, nutritive value

\section{Introdução}

Em regiões de pecuária leiteira no Brasil predominam pastagens de capim-brachiária (Brachiaria decumbens), capim-gordura (Melinis minutiflora), capim-setária (Setária anceps) e capimjaraguá (Hiparrhenia rufa) (SOARES et al., 2002). A utilização do capim-elefante de porte alto para pastejo é limitada pelo seu hábito de crescimento, resultante do rápido alongamento e amadurecimento do colmo e esse porte muitas vezes fora do alcance dos animais, o que acarreta necessidade de roçagem após pastejo, visando à remoção dos resíduos fibrosos e estímulo de surgimento de rebrote novo com melhor qualidade. O uso de variedades de porte baixo com entrenós menores e maior relação folha/colmo que as variedades comuns possibilitam a implantação de sistema de pastejo (VEIGA et al., 1985), tanto para bovinos quanto para animais de pequeno porte como ovinos e caprinos.

O conhecimento das características físicas, estruturais, quantidade e composição químicabromatológica de forragem oferecida e consumida pelo animal são fatores importantes para alcançar elevados níveis de produção animal (BRÂNCIO et al., 2003). Além de auxiliar a identificar o melhor momento de inserir os animais no sistema de pastejo visando aumento de produtividade (JANUSCKIEWICZ et al., 2010). Entretanto, a composição bromatológica varia com a espécie forrageira, parte da planta, época do ano, temperatura, umidade, fertilidade de solo e manejo adotado (VAN SOEST, 1994) e o valor nutritivo varia de acordo com a composição química, digestibilidade dos nutrientes e consumo voluntário apresentado pelos animais (GAMA et al., 2009).

Uma forma de correlacionar produção de forragem e melhor momento de pastejo ou corte é através de interceptação luminosa (IL), pois, quando o dossel forrageiro intercepta $95 \%$ da radiação incidente os processos de senescência e alongamento do colmo ainda estão incipientes e a taxa de acúmulo de folhas com maior qualidade é máxima em detrimento a $100 \%$ de IL, momento este que assinala maior processo de senescência por sombreamento das folhas da parte inferior da planta (CARNEVALLI et al., 2006) e maior participação de colmo e material senescente, seguido por uma redução na qualidade da forragem no pasto (JANUSCKIEWICZ et al., 2010; SUN; WAGHORN; CLARK, 2010).

Mudanças na estrutura do pasto associado à interceptação luminosa que acarreta maior período entre pastejos sucessivos, assim como, menor altura do resíduo favorece a participação de colmo e material senescente no estrato pastejado (PACIULLO et al., 2001; TRINDADE et al., 2007; CARVALHO et al., 2009). Isto faz com que bovinos adquiram novas estratégias de adaptação (PEDROSO et al., 2004), apresentando variações no tempo de pastejo, taxa de bocado, massa do bocado e na qualidade da forragem ingerida (PALHANO et al., 2007).

O processo de intensificação da produção de leite requer o emprego de forrageiras de elevada capacidade de produção de matéria seca e boa qualidade nutricional, o que pode ser alcançada pela 
utilização de diversas forrageiras entre elas o capim elefante (SILVA, 2011). O capim-elefante de porte anão difere dos de porte alto por ter entrenós mais curtos, o que confere maior qualidade à forragem além de facilitar o manejo (CHAVES et al., 2013). Dentre os clones de capim-elefante de porte anão pode ser citado o cultivar 'BRS Kurumi' (CNPGL 92-198-7) com touceiras de formato semiaberto e o CNPGL 00-1-3 sendo que estes cultivares apresentam alturas 1,68 e 2,06 m aos 84 dias, respectivamente (ARAÚJO et al., 2011).

Tendo em vista que avaliação nutricional da amostragem da planta inteira não representa devidamente o material pastejado pelo animal (EUCLIDES; EUCLIDES FILHO, 1998) o uso de metodologias de amostragem mais adequadas são indicadas, principalmente ao se trabalhar com forragens ainda desconhecidas.

Devido o exposto, objetivou se neste trabalho avaliar o comportamento ingestivo de novilhas mestiças (Holandês x Zebu) e qualidade da forragem pastejada utilizando animal amostrador com extrusa esofágica, simulação de pastejo e avaliação da planta inteira de pastagem de 2 clones de capimelefante anão submetidas a 2 níveis de interceptação luminosa e a 2 alturas de resíduos pós-pastejo na Zona da Mata - MG.

\section{Material e Métodos}

O experimento foi desenvolvido no campo experimental de Coronel Pacheco, MG, da Embrapa Gado de Leite (CNPGL). O período experimental foi de dezembro de 2010 a abril de 2011. O clima da região é do tipo Cwa (mesotérmico) segundo Köppen, e definido como clima temperado chuvoso no verão e com inverno seco entre junho e setembro (Embrapa, 1980), na altitude de $435 \mathrm{~m}$. As coordenadas geográficas do local são $21^{\circ} 33^{\prime}$ de latitude Sul e $43^{\circ} 16^{\prime}$ de longitude Oeste. Os dados climáticos foram coletados no posto meteorológico do Campo Experimental do CNPGL.
O solo experimental da região é classificado como Neossolo Flúvico Tb Distrófico (EMBRAPA, 2006). A área experimental conteve um total de 24 piquetes com $300 \mathrm{~m}^{2}$ cada, adubados de acordo com análise do solo, com aplicação de $100 \mathrm{~kg} \mathrm{ha}^{-1}$ de $\mathrm{P}_{2} \mathrm{O}_{5}$ colocado manualmente no sulco de plantio, realizada durante a estação chuvosa, após cada pastejo foi realizada uma adubação de cobertura a lanço, com o equivalente a $50 \mathrm{~kg} \mathrm{ha}^{-1}$ da fórmula 20-05-20 (N-P-K). O plantio para estabelecimento das forragens foi realizado no início do período chuvoso do ano de 2008 (setembro-outubro) com espaçamento entre linhas de $80 \mathrm{~cm}$.

A amostragem e determinação da qualidade do pasto foram realizadas utilizando-se um delineamento inteiramente ao acaso (DIC), disposto em esquema fatorial ( $2 \times 3$ ), constituídos de 2 clones de capim-elefante ('BRS Kurumi' de porte baixo e o CNPGL 00-1-3 de porte intermediário) e 3 métodos de amostragem do pasto (planta inteira, extrusa e simulação manual do pastejo) com 12 repetições cada. Para isto, foi utilizado 1 animal amostrador (1 vaca fistulada no esôfago) segundo proposta de (SANTANA JUNIOR et al., 2014). Corte da planta inteira a altura $15 \mathrm{~cm}$ do solo e simulação manual do pastejo (SMP) de acordo com a metodologia descrita por Cook (1964), consistindo em colheita de $\pm 500 \mathrm{~g}$ de amostras, realizada manualmente, após um período prévio de observação do comportamento do pastejo dos animais, por um amostrador devidamente treinado, objetivando obter uma porção da planta similar àquela selecionada pelos animais. Em seguida, as amostras foram secas em estufas ventiladas à temperatura de $55{ }^{\circ} \mathrm{C}$, durante 72 horas, moídas em moinho com peneira de $1 \mathrm{~mm}$ e encaminhada á análises química-bromatológica.

O comportamento ingestivo foi avaliado utilizando-se um delineamento inteiramente ao acaso, em esquema fatorial $(2 \times 2 \times 2)$ constituídos de 2 clones de capim-elefante anão ('BRS Kurumi' e CNPGL 00-1-3), 2 frequências de desfolhação, 
conforme a interceptação luminosa (90 e 95\%) e 2 alturas de resíduo pós-pastejo (30 e $50 \mathrm{~cm}$ ) com 3 repetições cada, utilizando 2novilhas mestiças (Holandês x Zebu) de 8 meses de idade com peso médio de $250 \mathrm{Kg}$, incluindo 2 ou 3 animais adicionais como "mob grazing" (MISLEVY; MOTT; MARTIN, 1981) para alcance da altura estabelecida de resíduo pós-pastejo em período de 2 dias de ocupação.

A entrada dos animais nos piquetes deuse quando os mesmos apresentavam 90 e $95 \%$ de interceptação luminosa no dossel, alturas equivalentes a $75 \mathrm{~cm}$ no 'BRS Kurumi' e 1,30 cm para o clone CNPGL 00-1-3, respectivamente, monitorado com um aparelho (DECAGON, modelo LP80), tomando-se 10 estimativas de interceptação luminosa em cada piquete. A altura de saída dos animais, no segundo dia de pastejo, ocorreu quando o resíduo da forragem apresentava altura de 30 e $50 \mathrm{~cm}$, medido em 20 pontos diferentes em cada piquete, com uma régua graduada em centímetros, de acordo com o tratamento disposto.

Avaliação da massa e da taxa de bocado (bocados/minuto)foi realizada observando-se a vaca fistulada no esôfago (BISHOP; FROSET, 1970), no dia anterior a avaliação do comportamento dos animais. $\mathrm{O}$ animal foi colocado em uma baia e submetido a jejum prévio de alimentos sólidos por 12 horas.No dia da colheita, as cânulas foram removidas do animal fistulado e substituídas por bolsa coletora de lona sintética de fundo telado, ajustada abaixo da fístula, para auxiliar a drenagem da saliva e posteriormente o animal conduzido à área experimental, pastejando livremente por 30 minutos nos piquetes referentes a cada repetição antes de serem pastejados pelas novilhas (LOPES et al., 1997). Realizava-sede modo visual a contagem do número de bocados, em quatro tempos de quinze segundos para determinação da taxa de bocados (bocados/min) segundo metodologia adotada por Trevisan et al. (2004).
Ao fim desse período, coletava-se o material da extrusa via cânula esofágica e acondicionava-se em sacos plásticos, para posterior pesagem. Amassa do bocado (gMS/Bocado) foi determinada através do peso da matéria seca total do material colhido pelo animal fistulado, dividido pelo número de bocados realizados na colheita da forragem conforme descrito por Tharmaraj et al. (2003). As amostras foram divididas em duas partes (subamostras): uma para determinação da proporção relativa das frações da planta na dieta (folha, colmo e material morto) e a outra armazenada em congelador, visando posterior análise químico-bromatológica.

As análises químico-bromatológica foram realizadas no Laboratório de Nutrição Animal da Universidade Federal Rural do Rio de Janeiro (UFRRJ). Foram analisados os teores de matéria seca e de proteína bruta (AOAC, 1990), fibra insolúveis em detergente neutro (FDN) e ácido (FDA) e de lignina foram analisadas de acordo com a metodologia descrita por Van Soest, Robertson e Lewis (1991) e a determinação da digestibilidade in vitro de acordo Tilley e Terry (1963) adaptada para o fermentador ruminal Daisy, conforme descrito por Santos et al. (2000).

Os dados foram submetidos à análise de variância e as médias de tratamentos comparadas pelo teste de Tukey a 5\% de probabilidade, utilizando-se o pacote estatístico SAEG 9.1 (2007).

\section{Resultados e Discussão}

Conforme apresentado na figura 1, o experimento iniciou com alta precipitação no mês de dezembro, apresentando queda no volume até o mês de abril, devido à baixa precipitação a partir de maio, o crescimento dos clones do capim-elefante foi prejudicado, não apresentando crescimento suficiente para adoção do manejo pela intensidade de interceptação luminosa. Motivo pelo qual a avaliação ocorreu somente no período de dezembro a abril. 
Figura 1. Precipitação e temperaturas máximas, mínimas registradas durante o período experimental.

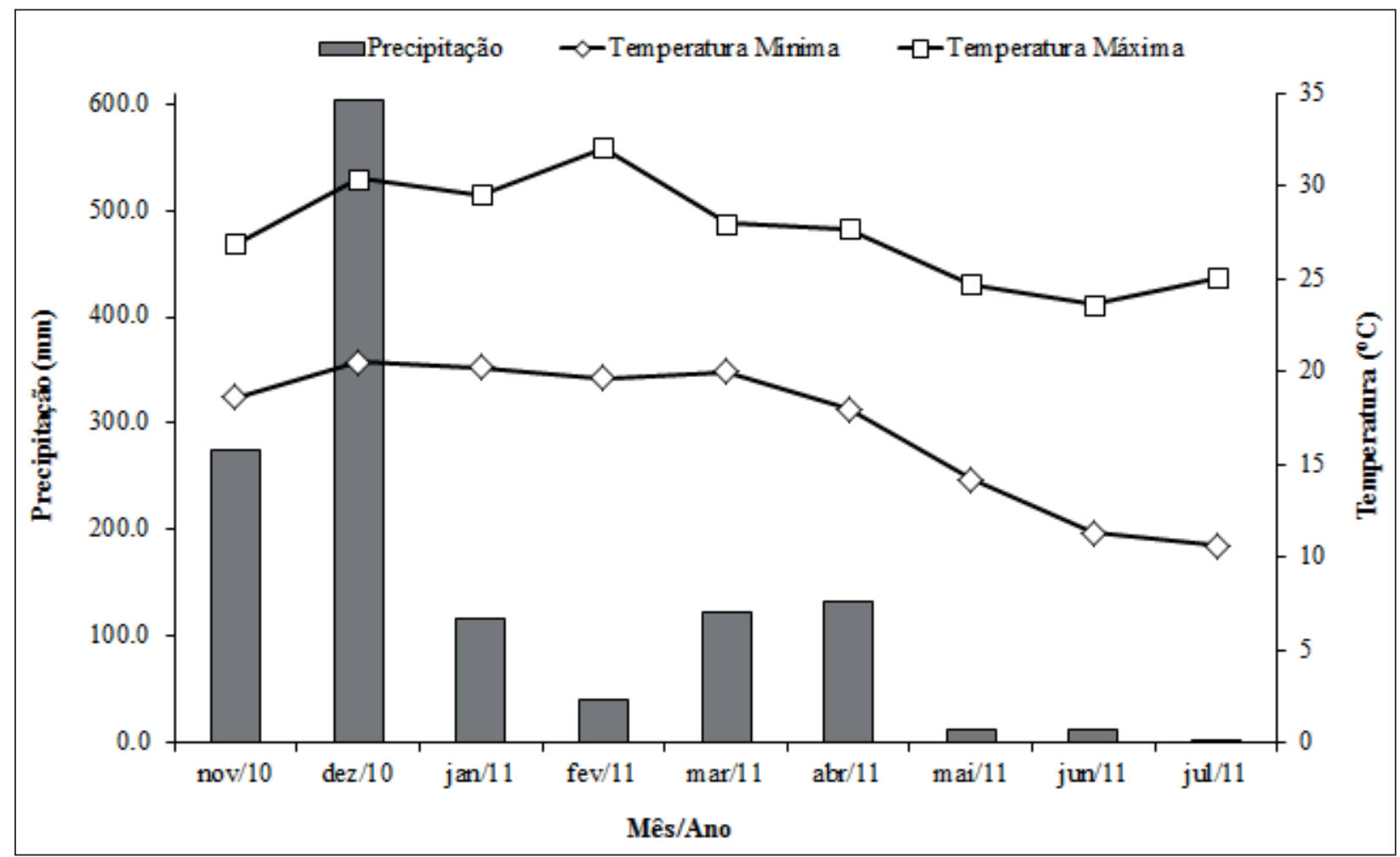

Fonte: Elaboração dos autores.

Entre os parâmetros avaliados na análise bromatológica, a proteína bruta (PB), fibra em detergente neutro (FDN) e ácido (FDA), celulose, lignina e digestibilidade in vitro da matéria seca (DIVMS) foram influenciadas pela metodologia de avaliação $(\mathrm{P}<0,05)$. Os teores de $\mathrm{PB}$ nas amostras dos clones de capim-elefante anão apresentaram maiores valores quando quantificados para os métodos da extrusa e simulação manual do pastejo (SMP), em relação aquele da planta inteira. Teores referentes à FDA e FDN na matéria seca foram decrescente em relação as metodologias extrusa, avaliação da planta inteira e SMP, respectivamente, já os teores de celulose e lignina foram superiores na metodologia da extrusa em relação à avaliação nas amostras de planta inteira e SMP, e a DIVMS foi menor na planta inteira em relação à extrusa e SMP (Tabela 1).

Segundo Euclides, Macedo e Oliveira (1992), a metodologia de SMP é uma alternativa à utilização de animais com extrusa para avaliação de forragem a pasto. Quanto à contaminação do material da extrusa, este pode ser volatilizado durante o processamento de secagem em estufa ventilada (GOES et al., 2003). A diferença de qualidade entre o método de SMP e extrusa em relação à colheita de planta inteira utilizando quadrado metálico não leva em consideração à seleção de folhas em detrimento a material de baixo valor nutritivo como caule e material senescente, sendo este método recomendado apenas para determinação da quantidade de forragem no pasto (ZANINETTI et al., 2010). Diferença do teor de PB entre extrusa e SMP é contraditória ora apresentando diferença (CLIPES et al., 2005), ora semelhança (MORAES et al., 2005). Estes resultados demonstram que existe uma série de fatores que podem influenciar na composição bromatológica de amostras obtidas via SMP, diante da não observação de todos os hábitos de pastejo dos animais, variação entre amostradores, espécie forrageira, dentre outros. 
Tabela 1. Teores médios e respectivos coeficientes de variação (CV) da proteína bruta (PB), fibra em detergente neutro (FDN), fibra em detergente ácido (FDA), lignina, celulose e digestibilidade in vitro da matéria seca (DIVMS) da forragem dos clones capim elefante anão ('BRS Kurumi' e CNPGL 00-1-3) de acordo com os métodos de amostragem (planta inteira, extrusa, e simulação manual de pastejo (SMP).

\begin{tabular}{ccccc}
\hline \multirow{2}{*}{ Itens } & \multicolumn{3}{c}{ Metodologia } & \multirow{2}{*}{ CV(\%) } \\
\cline { 2 - 4 } & Planta inteira & Extrusa & SMP & 20,0 \\
PB & $9,6 \mathrm{~B}$ & $13,3 \mathrm{~A}$ & $13,6 \mathrm{~A}$ & 9,1 \\
FDN & $64,2 \mathrm{~B}$ & $68,9 \mathrm{~A}$ & $61,0 \mathrm{C}$ & 5,6 \\
FDA & $33,4 \mathrm{~B}$ & $34,9 \mathrm{~A}$ & $32,4 \mathrm{C}$ & 8,9 \\
Celulose & $30,4 \mathrm{~B}$ & $31,7 \mathrm{~A}$ & $30,0 \mathrm{~B}$ & 16,6 \\
Lignina & $2,9 \mathrm{~B}$ & $3,5 \mathrm{~A}$ & $2,9 \mathrm{~B}$ & 3,7 \\
DIVMS & $66,1 \mathrm{C}$ & $71,3 \mathrm{~A}$ & $74,2 \mathrm{~A}$ & \\
\hline
\end{tabular}

Médias seguidas de mesma letra nas linhas não diferem pelo teste Tukey a 5\% de probabilidade.

Fonte: Elaboração dos autores.

Foi encontrado maior teor de FDN, FDA em relação amostragem da planta inteira e SMP e, da celulose e lignina para o material recuperado da extrusa em relação à planta inteira e SMP, sendo que estes dois últimos não diferiram entre si $(\mathrm{P}>0,05)$. Possivelmente, isto ocorreu devido ao processo de secagem, acarretado pela alta concentração de umidade proveniente da saliva. Resultados como estes estão associados à ocorrência da reação de Maillard com formação do complexo hemicelulose e proteína com a lignina, durante a pré-secagem do material, em razão do elevado teor de umidade oriundo da saliva, o qual predispõe a amostra a esta reação (VAN SOEST, 1994). Outra explicação para esta diferença pode ser devido à maior lixiviação pela saliva de constituintes (carboidratos solúveis, proteínas e minerais) solúveis das amostras de forragem coletada por animal fistulado que passa através do orifício de drenagem da bolsa coletora (HOEHNE; CLANTON; STREETEK, 1967).

A DIVMS da amostra de clones de capimelefante anão obteve menores valores para planta inteira. Isto reflete a alta concentração de material lignificado em amostras de planta inteira, reforçando o conceito do pastejo seletivo, no qual as folhas são preferidas, em relação aos colmos e material morto. O que confirma que a metodologia da planta inteira não é bom indicativo da forragem consumida pelo animal (ZANINETTI et al., 2010). Já a SMP por não apresentar diferença entre a colheita pela extrusa $(\mathrm{P}>0,05)$ serve como alternativa ao uso de animais fistulados o que corroboram com Lista et al. (2007) que confirmam o uso desta metodologia em trabalho com capim-mombaça e capim-elefante.

Os teores de matéria mineral e celulose foram influenciados pela interação entre métodos de amostragem da forragem e clones $(\mathrm{P}<0,05)$ (Tabela 2) para o 'BRS Kurumi' foi encontrado diferença entre a colheita com animal fistulado e planta inteira e SMP $(\mathrm{P}<0,05)$. No entanto, planta inteira e SMP não apresentaram diferença entre si para matéria mineral $(\mathrm{P}>0,05)$. O mesmo ocorrendo para os clones ao analisar o material recuperado na extrusa $(\mathrm{P}>0,05)$. Resultados para matéria mineral de amostras providas de extrusa são contraditórios, pois ao mesmo tempo em que pode ocorrer aumento (EUCLIDES; MACEDO; OLIVEIRA, 1992) pode ocorrer lixiviação (HOEHNE; CLANTON; STREETEK, 1967), devido à contaminação pela saliva que pode adicionar minerais ou carrear pela tela.

Em relação ao teor de celulose, este apresentou diferença entre os clones ao analisar plantas inteiras $(\mathrm{P}<0,05)$. O maior valor no teor de celulose encontrado na extrusa foi para o 'BRS Kurumi' em relação à planta inteira e $\mathrm{SMP}(\mathrm{P}<0,05)$. No entanto, 
o CNPGL 00-1-3 não apresentou diferença para os métodos de análises $(\mathrm{P}>0,05)$. $\mathrm{O}$ resultado para $\mathrm{o}$ 'BRS Kurumi' pode estar relacionado ao processo de secagem conforme determinado (VAN SOEST, 1994) e lixiviação de constituintes solúveis. Entretanto, o mesmo não aplica ao CNPGL 00-1-3.

Tabela 2. Teores de matéria mineral e lignina na MS da forragem, para os diferentes métodos de amostragem de pastejo (planta inteira, extrusa, e simulação manual de pastejo (SMP)) e os clones de capim-elefante

\begin{tabular}{ccccc}
\hline \multirow{2}{*}{ Clones } & \multicolumn{3}{c}{ Metodologia } & \multirow{2}{*}{ CV $(\%)$} \\
\cline { 2 - 3 } & Planta inteira & Extrusa & SMP \\
\hline 'BRS Kurumi' & $13,0 \mathrm{Aa}$ & Matéria Mineral & $13,6 \mathrm{Aa}$ \\
CNPGL 00-1-3 & $11,1 \mathrm{Ba}$ & $11,7 \mathrm{Ab}$ & $10,7 \mathrm{Ba}$ \\
\hline & $11,2 \mathrm{Aa}$ & \multirow{3}{*}{8,9} \\
\hline 'BRS Kurumi' & $28,9 \mathrm{Bb}$ & Celulose & $29,4 \mathrm{Ab}$ \\
CNPGL 00-1-3 & $31,9 \mathrm{Aa}$ & $31,7 \mathrm{Aa}$ & $30,6 \mathrm{Aa}$ & \\
\hline
\end{tabular}

Médias seguidas de letras iguais minúscula na linha e maiúscula na coluna não diferem pelo teste Tukey a 5\% de probabilidade.

Fonte: Elaboração dos autores.

Os constituintes PB, FDA e celulose foram influenciados pelo índice de interceptação luminosa no pré-pastejo e clones $(\mathrm{P}<0,05)($ Tabela4).

$\mathrm{O}$ teor de FDA variou entre os métodos de amostragem para a interceptação luminosa de 90 $\%$, com maior valor para o método de colheita pela extrusa $(\mathrm{P}<0,05)$. Entretanto, não houve diferença entre os métodos de colheita de planta inteira e SMP $(\mathrm{P}>0,05)$ (Tabela 3$)$. Teores mais elevados de FDA nas amostras obtidas por meio da extrusa podem estar relacionados ao processo de secagem, acarretado pela alta concentração de umidade proveniente da saliva (CLIPES et al., 2005). Além disso, a seleção de forma criteriosa dos observadores por maior relação folha/colmo, ou seja, com alto conteúdo de carboidratos solúveis, podem ter subestimados os resultados de FDA nas amostras de pastejo simulado em relação ao pastejo do próprio animal. Analisando-se o teor de FDA na IL de 95\% obteve maiores valores para extrusa e planta inteira em relação ao $\mathrm{SMP}(\mathrm{P}<0,05)$. Estes resultados são condizentes, principalmente, relativos aos valores de planta inteira devido à presença de grande quantidade de material senescente e colmo, frações comumente não selecionadas pelo animal (GOES et al., 2003), exceto nos casos de baixa oferta de forragem e lixiviação de constituintes solúveis em caso da extrusa.

Observa-se que a FDA foi modificada pelas interceptações luminosas de acordo com os métodos de amostragem da forragem. Para planta inteira, o aumento da IL aumentou o valor de FDA de 32,9 para $34,8 \%$. Com o prolongamento do intervalo entre desfolhações, há tendência de incremento na participação de colmos, e consequente aumento da FDA (Tabela 3). 
Tabela 3.Teor de Fibra em detergente ácido (FDA) em porcentagem na MS de capim-elefante anão ('BRS Kurumi' e CNPGL 00-1-3) em diferentes métodos de amostragem de pastejo (planta inteira, extrusa, e simulação manual de pastejo (SMP)) em função das interceptações luminosas no pré-pastejo.

\begin{tabular}{ccccc}
\hline \multirow{2}{*}{$\mathrm{IL}(\%)$} & \multicolumn{3}{c}{ Metodologia } & \multirow{2}{*}{$\mathrm{CV}(\%)$} \\
\cline { 2 - 4 } & Planta inteira & Extrusa & SMP & \\
\hline 90 & $32,9 \mathrm{Bb}$ & $35,5 \mathrm{Aa}$ & $33,0 \mathrm{Ab}$ & 5,6 \\
95 & $34,8 \mathrm{Aa}$ & $34,5 \mathrm{Aa}$ & $31,9 \mathrm{Ab}$ & \\
\hline
\end{tabular}

Médias seguidas de letras iguais minúscula na linha e maiúscula na coluna não diferem pelo teste Tukey a 5\% de probabilidade.

Fonte: Elaboração dos autores.

Houve efeito de interação $(\mathrm{P}<0,05)$ entre clones de capim-elefante e de interceptação luminosa sobre os teores de PB, FDA e celulose (Tabela 4). O clone 'BRS Kurumi' na IL de 90\% apresentou maior teor de proteína em relação ao clone CNPGL 00-1-3 na IL de 95\% $(\mathrm{P}<0,05)$. Já o clone CNPGL
00-1-3 não apresentou diferença para o teor de $\mathrm{PB}$ nas IL de $90 \%$ e $95 \%$ (P>0,05). Para o clone 'BRS Kurumi' a alteração nos teores de PB é condizente uma vez que há redução do valor nutritivo com maior idade da planta (LEITE; QUEIROZ FILHO; SILVA, 2000).

Tabela 4. Teores de proteína bruta (PB) na MS, fibra em detergente ácido (FDA) e celulose conforme os clones de capim-elefante ('BRS Kurumi’ e CNPGL 00-1-3) e a interceptação luminosa no pré-pastejo.

\begin{tabular}{|c|c|c|c|}
\hline \multirow{2}{*}{ Clones } & \multicolumn{2}{|c|}{ IL (\%) } & \multirow{2}{*}{$\mathrm{CV}(\%)$} \\
\hline & 90 & 95 & \\
\hline \multicolumn{4}{|c|}{ Proteína Bruta (PB) } \\
\hline 'BRS Kurumi' & $14,7 \mathrm{Aa}$ & $12,8 \mathrm{Ab}$ & \\
\hline CNPGL 00-1-3 & $10,4 \mathrm{Ba}$ & $11,1 \mathrm{Ba}$ & 20,0 \\
\hline \multicolumn{4}{|c|}{ FDA } \\
\hline 'BRS Kurumi' & $32,8 \mathrm{Ba}$ & $33,5 \mathrm{Aa}$ & \\
\hline CNPGL 00-1-3 & $34,8 \mathrm{Aa}$ & $33,4 \mathrm{Ab}$ & 5,6 \\
\hline \multicolumn{4}{|c|}{ Celulose } \\
\hline 'BRS Kurumi' & $29,3 \mathrm{Ba}$ & $30,7 \mathrm{Aa}$ & \\
\hline CNPGL 00-1-3 & $31,9 \mathrm{Aa}$ & $31,0 \mathrm{Aa}$ & 8,9 \\
\hline
\end{tabular}

Médias seguidas de letras iguais minúscula na linha e maiúscula na coluna não diferem pelo teste Tukey a 5\% de probabilidade. Fonte: Elaboração dos autores.

Os valores de PB encontrados neste trabalho são condizentes com aqueles relatados por Chaves et al. (2013), trabalhando com os mesmos clones de capim-elefante anão 'BRS Kurumi' e CNPGL 00$1-3$.

O clone CNPGL 00-1-3 apresentou maior teor de FDA em relação ao 'BRS Kurumi' $(\mathrm{P}<0,05)$ na interceptação luminosa de $90 \%$. Na IL de $95 \%$ não foi observado diferença entre os clones $(\mathrm{P}>0,05) \mathrm{o}$ mesmo ocorreu com o clone 'BRS Kurumi' que não apresentou diferença entre IL de 90 e $95 \%(\mathrm{P}>0,05)$ para este parâmetro. No entanto, o clone CNPGL 00-1-3 apresentou maior teor de FDA na IL de 90\%. Chaves et al. (2013) estudando os mesmos clones sob manejo de interceptação luminosa (90 e 95 $\%)$ e alturas de resíduo (30 e $50 \mathrm{~cm}$ ), encontraram teores médios de FDA igual a 40\%, valor superior ao do presente trabalho, porém, vale ressaltar que 
no trabalho desses autores, o teor encontrado é referente à planta inteira.

O teor de celulose foi influenciado pela interação entre clone e interceptação luminosa $(\mathrm{P}<0,05)$ em que o clone CNPGL 00-1-3 apresentou maior teor em relação ao clone 'BRS Kurumi' a IL de 90 \%, este resultado está diretamente relacionado ao maior teor de FDA encontrado para o CNPGL 00-1-3, para os intervalos de IL não foi apresentado diferença entre os clones $(\mathrm{P}>0,05)$ (Tabela 4$)$.
Os teores de celulose e lignina foram influenciados pela interação clone e resíduo póspatejo $(\mathrm{P}<0,05)$. Na altura de resíduo de $30 \mathrm{~cm}$ o clone CNPGL 00-1-3 apresentou maior teor de celulose em relação ao 'BRS Kurumi'. Não havendo diferença para as outras combinações para o teor de celulose e altura de resíduo $(\mathrm{P}>0,05)$. Na altura de $30 \mathrm{~cm}$ de resíduo, o clone CNPGL 001-3 apresentou maior teor de lignina em relação ao 'BRS Kurumi', já na altura de resíduo de 50 $\mathrm{cm}$, maior valor foi registrado para o clone 'BRS Kurumi’ em relação ao CNPGL 00-1-3(Tabela 5).

Tabela 5. Teor de celulose e lignina na MS da forragem dos clones de capim-elefante ('BRS Kurumi' e CNPGL 001-3) nas alturas de resíduo pós-pastejo de 30 e $50 \mathrm{~cm}$.

\begin{tabular}{|c|c|c|c|}
\hline \multirow{2}{*}{$\begin{array}{l}\text { Resíduo } \\
(\mathrm{cm})\end{array}$} & \multicolumn{2}{|c|}{ Clones } & \multirow{2}{*}{$\mathrm{CV}(\%)$} \\
\hline & 'BRS Kurumi' & CNPGL 00-1-3 & \\
\hline \multicolumn{4}{|c|}{ Celulose } \\
\hline 30 & $29,3 \mathrm{Ab}$ & $31,9 \mathrm{Aa}$ & \\
\hline 50 & $30,7 \mathrm{Aa}$ & $31,0 \mathrm{Aa}$ & 7,5 \\
\hline \multicolumn{4}{|c|}{ Lignina } \\
\hline 30 & $2,7 \mathrm{Bb}$ & $3,1 \mathrm{Aa}$ & \\
\hline 50 & $3,5 \mathrm{Aa}$ & $3,0 \mathrm{Ab}$ & 16,6 \\
\hline
\end{tabular}

Médias seguidas de letras iguais minúscula na linha e maiúscula na coluna não diferem pelo teste Tukey a 5\% de probabilidade. Fonte: Elaboração dos autores.

Silva et al. (2009) trabalhando com capimmombaça com duas alturas de resíduo pós-pastejo $(30$ e $50 \mathrm{~cm})$ e dois intervalos de pastejo $(95$ e $100 \%$ de IL), também observou que os tratamentos de resíduo de $50 \mathrm{~cm}$ e de pastejo realizado com $95 \%$ de IL foram os que apresentaram os maiores teores de lignina.
Houve efeito de interação entre IL e altura de resíduo para os teores de $\mathrm{PB}(\mathrm{P}<0,05)$, onde altura de resíduo pós-pastejo de $30 \mathrm{~cm}$ de altura apresentou maior teor de PB na IL de (95\%), já para a altura de resíduo de $50 \mathrm{~cm}$ foi encontrado maior teor de $\mathrm{PB}$ para IL de 90\%(Tabela 6).

Tabela 6. Teor de proteína bruta (PB) na MS da forragem capim-elefante ('BRS Kurumi’ e CNPGL 00-1-3), de acordo com a altura do resíduo pós pastejo (30 e $50 \mathrm{~cm})$ e interceptação luminosa $(90$ e 95\%).

\begin{tabular}{|c|c|c|c|}
\hline \multirow{2}{*}{$\begin{array}{l}\text { Resíduo } \\
(\mathrm{cm})\end{array}$} & \multicolumn{2}{|c|}{ IL(\%) } & \multirow{2}{*}{$\mathrm{CV}(\%)$} \\
\hline & 90 & 95 & \\
\hline 30 & $12,1 \mathrm{Ab}$ & $13,3 \mathrm{Aa}$ & \\
\hline 50 & $12,9 \mathrm{Aa}$ & $10,6 \mathrm{Bb}$ & 20,0 \\
\hline
\end{tabular}

Médias seguidas de letras iguais minúscula na linha e maiúscula na coluna não diferem pelo teste Tukey a 5\% de probabilidade. Fonte: Elaboração dos autores. 
Segundo Gomide et al. (2008), a medida que a gramínea cresce, novas folhas surgem nos perfilhos. Contudo, o alongamento do colmo ocorre simultaneamente e tende a se intensificar com períodos de crescimento mais longos, reduzindo a relação folha/colmo e, consequentemente, o valor nutritivo da forragem, o que justifica os melhores resultados obtidos para $90 \%$ IL para $50 \mathrm{~cm}$ de resíduo, obtido no presente trabalho. Já para o resíduo de 30 $\mathrm{cm}$ de altura, o que pode ter ocorrido é que ambos clones não tenham atingido o potencial máximo de crescimento e, consequentemente, produzido respostas inferiores àquelas esperadas quanto aos teores de PB, uma vez que, sobretudo, seus conteúdos de clorofila e demais constituintes ricos em $\mathrm{N}$, estivessem aquém daqueles normalmente encontrados, limitando suas respostas em PB.

Os parâmetros, altura, massa de forragem, relação folha/colmo e densidade de forragem $(\mathrm{kg}$ $\mathrm{MS} / \mathrm{cm})$, avaliados no período pré-pastejo foram influenciados pelos clones e IL $(\mathrm{P}<0,05)$ (Tabela 7). Oclone 'BRS Kurumi' apresentou menor altura e massa de forragem e maiores relação folha/colmo e densidade de forragem em relação ao CNPGL 00-1-3. O manejo do pasto à IL de $90 \%$ apresentou menores alturas, massa e densidade de forragem e maior relação folha/colmo em relação à IL de 95\%. A taxa de bocado (bocado/min) e a proporção de folhas foram influenciadas pelo clone $(\mathrm{P}<0,05) \mathrm{em}$ que o clone 'BRS Kurumi' apresentou maior número de bocados por minuto e proporção de folhas em relação ao CNPGL 00-1-3.

Tabela 7. Valores médios de altura de planta no pré-pastejo, período de descanso, massa seca total, densidade de forragem e relação folha-colmo conforme clones de capim-elefante ('BRS Kurumi’ e CNPGL 00-1-3) e interceptação luminosa.

\begin{tabular}{|c|c|c|c|c|c|}
\hline \multirow[b]{2}{*}{ Variáveis } & \multicolumn{2}{|c|}{ Clones } & \multicolumn{2}{|c|}{$\underline{\operatorname{IL}(\%)}$} & \multirow{2}{*}{$\mathrm{CV}(\%)$} \\
\hline & 'BRS Kurumi' & CNPGL 00-1-3 & 90 & 95 & \\
\hline $\begin{array}{l}\text { Altura de planta no pré- } \\
\text { pastejo }(\mathrm{cm})\end{array}$ & $96,0 b$ & $169,0 \mathrm{a}$ & $125,2 b$ & $139,8 \mathrm{a}$ & 7,1 \\
\hline Massa de forragem $(\mathrm{kg} / \mathrm{ha})$ & $6.945,0 \mathrm{~b}$ & $10.301,3 \mathrm{a}$ & $7.709,2 b$ & $9.537,2 \mathrm{a}$ & 16,3 \\
\hline Relação folha/colmo & $1,1 \mathrm{a}$ & $0,73 b$ & $1,01 \mathrm{a}$ & $0,81 \mathrm{~b}$ & 19,9 \\
\hline $\begin{array}{l}\text { Densidade de forragem }(\mathrm{kg} \\
\mathrm{MS} / \mathrm{cm})\end{array}$ & $58,8 \mathrm{a}$ & $50,9 b$ & $51,6 b$ & $58,1 \mathrm{a}$ & 12,6 \\
\hline
\end{tabular}

Médias seguidas por letras iguais, minúscula na linha e maiúscula na coluna não diferem entre si pelo teste Tukey a 5\% de probabilidade.

Fonte: Elaboração dos autores.

Não houve efeito de interceptação luminosa e altura de resíduo na taxa de bocado média 26,2 bocados/min. A maior proporção de folhas e menor altura no pré-pastejo demonstra a facilidade de apreensão da forragem para este mesmo clone (Tabela 8). Em baixa oferta ou alturas elevadas de forragem, há aumento na taxa de bocado que pode atingir a 60 bocados $\min ^{-1}$ para bovinos adultos, enquanto que a metade deste valor, cerca de 30 bocados min. $^{-1}$, indica situação de conforto para os animais (SILVA et al., 2011) estando a taxa de bocado encontrada neste trabalho próximo a este valor.

O percentual de material morto foi influenciado pela altura de resíduo pós-pastejo $(\mathrm{P}<0,05)$, sendo maior na altura de $50 \mathrm{~cm}$ (Tabela 8). Pastos manejados à elevada altura proporcionam um sombreamento na base do dossel aumentando a incidência de material senescente. 
Tabela 8. Material morto, relação folha/colmo, percentagem de folha das amostras de extrusa e taxa de bocado (bocado/min), conforme clone de capim-elefante ('BRS Kurumi' e CNPGL 00-1-3), interceptação luminosa (IL) e altura do resíduo de pastejo.

\begin{tabular}{|c|c|c|c|c|c|c|}
\hline \multicolumn{2}{|c|}{ Clone } & \multicolumn{2}{|c|}{ IL (\%) } & \multicolumn{2}{|c|}{ Resíduo (cm) } & \multirow{2}{*}{$\mathrm{CV}(\%$} \\
\hline 'BRS Kurumi' & CNPGL 00-1-3 & 90 & 95 & 30 & 50 & \\
\hline \multicolumn{7}{|c|}{ - } \\
\hline $32,2 \mathrm{a}$ & $20,2 \mathrm{~b}$ & $25,3 \mathrm{a}$ & $27,1 \mathrm{a}$ & $26,7 \mathrm{a}$ & $25,7 \mathrm{a}$ & 36,6 \\
\hline \multirow{3}{*}{95,0 a } & & entagen & olha ver & & -------- & \\
\hline & $88,1 \mathrm{~b}$ & 89,3 a & 93,8 a & 92,4 a & 90,7 a & 8,11 \\
\hline & & centual & rial Mo & 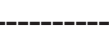 & --- & \\
\hline $0,68 \mathrm{a}$ & $0,94 \mathrm{a}$ & $0,77 \mathrm{a}$ & $0,85 \mathrm{a}$ & $0,57 \mathrm{~b}$ & $1,05 \mathrm{a}$ & 75,7 \\
\hline
\end{tabular}

Médias seguidas por letra iguais não diferem entre si pelo teste de Tukey a 5\% de probabilidade.

Fonte: Elaboração dos autores.

A massa do bocado foi influenciada pelos clones e pela interação entre clone e altura de resíduo $(\mathrm{P}<0,05)$. O clone 'BRS Kurumi' apresentou maior média $(0,61 \mathrm{gMS} /$ Bocado $)$ na altura de resíduo de $50 \mathrm{~cm}$ em relação a $(0,38 \mathrm{gMS} /$ Bocado) no resíduo de $30 \mathrm{~cm}$ de altura. Na altura de resíduo de $50 \mathrm{~cm}$ o 'BRS Kurumi' apresentou maior taxa de bocado em relação ao CNPGL 00-1-3 (Tabela 9). Da mesma forma, Lira (2009) observou maior massa de bocado em resíduos mais altos (0,83 gMS/Bocado). Não houve diferença entre os clones na altura de resíduo de $30 \mathrm{~cm}(\mathrm{P}>0,05)$.

Tabela 9. Massa do bocado (gMS/Bocado) dos clones de capim-elefante anão('BRS Kurumi' e CNPGL 00-1-3) em altura de resíduo pós pastejo.

\begin{tabular}{ccc}
\hline \multirow{2}{*}{ Clone } & \multicolumn{2}{c}{ Resíduo (cm) } \\
\cline { 2 - 3 } & 30 & 50 \\
\hline BRS Kurumi & $0,38 \mathrm{Ab}$ & $0,61 \mathrm{Aa}$ \\
CNPGL 00-1-3 & $0,49 \mathrm{Aa}$ & $0,42 \mathrm{Ba}$ \\
\hline CV (\%) & \multicolumn{2}{c}{20,2} \\
\hline
\end{tabular}

Médias seguidas por letras iguais, minúscula na linha e maiúscula na coluna não diferem entre si pelo teste Tukey a 5\% de probabilidade.

Fonte: Elaboração dos autores.

Devido ao hábito de crescimento do clone CNPGL 00-1-3, este dificilmente alcança o rebaixamento de 30 e $50 \mathrm{~cm}$ de resíduo, o que acarreta em maior relação de colmos e consequentemente maior teor de FDA no prépastejo, sobretudo para pastos manejados sob maiores alturas pré-pastejo (95\% IL).

A estrutura, altura e densidade, assim como a maior proporção de folhas do 'BRS Kurumi' facilitou maior aporte de forragem devido a maior taxa de bocado e massa do bocado realizado pelo animal, o que corrobora com Pereira et al. (2013) que ao trabalhar com estes dois clones relataram que o porte e densidade de forragem do 'BRS Kurumi' propicia seu uso em sistema de pastejo em detrimento ao CNPGL 00-1-3 mais indicado para formação de capineira.

\section{Conclusões}

O uso do clone 'BRS Kurumi' manejado sob interceptação luminosa de $90 \%$ e altura de resíduo de $30 \mathrm{~cm}$ para pastejo, facilita o forrageamento por novilhas, comprovados pela taxa e massa do bocado.

A metodologia da simulação manual de pastejo com avaliador treinado possibilita uma estimativa aceitável da forragem selecionada pelos animais em pastejo e amostragem de planta inteira não representa a dieta selecionada pelo animal.

O clone 'BRS kurumi’ é propício para sistema 
de pastejo e o CNPGL 00-1-3 mais indicado à formação de capineiras.

\section{Agradecimento}

À CAPES, pela concessão da bolsa de estudo e ao $\mathrm{CNPq}$ e à FAPEMIG pelo auxílio financeiro do projeto.

\section{Referências}

ARAÚJO, S. A. C.; VASQUEZ, H. M.; SILVA, J. F. C.; LIMA, E. S.; LISTA, F. N.; DEMINICIS, B. B.; CAMPOS, P. R. S. S. Produção de matéria seca e composição bromatológica de genótipos de capimelefante anão. Archivos de Zootecnia, Cordoba, v. 60, n. 229, p. 83-91, 2011.

ASSOCIATION OF OFFICIAL ANALYTICAL CHEMISTS - AOAC. Official methods of analysis. v. I. $15^{\text {th }}$ ed. Arlington: AOAC International, 1990. $117 \mathrm{p}$.

BISHOP, J. L.; FROSET, J. A. Improved techniques in esophageal fistulization of sheep. American Journal of Veterinary Research, Chicago, v. 31, n. 8, p. 1505-1507, 1970.

BRÂNCIO, P. A.; EUCLIDES, V. B.; NASCIMENTO JUNIOR, D.; FONSECA, D. M.; ALMEIDA, R. G.; MACEDO, M. C. M.; BARBOSA, R. M. Avaliação de três cultivares de Panicum maximum Jacq. sob pastejo comportamento ingestivo de bovinos. Revista Brasileira de Zootecnia, Viçosa, MG, v. 32, n. 1, p. 1045-1053, 2003.

CARNEVAlli, R. A.; SILVA, S. C.; BUENO, A. A. O.; UEBELE, M. C.; BUENO, F. O.; HODGSON, J.; SILVA, G. N.; MORAIS, J. P. G. Herbage production and grazing losses in Panicum maximum cv. Mombaça under four grazing managements. Tropical Grasslands, Brisbane, v. 40, p. 165-176, 2006.

CARVALHO, P. C. F.; TRINDADE, J. K.; MEZZALIRA, J. C.; POLI, C. H. E. C.; NABINGER, C.; GENRO, T. C. M.; GONDA, H. L. Do bocado ao pastoreio de precisão: compreendendo a interface planta-animal para explorar a multi-funcionalidade das pastagens. Revista Brasileira de Zootecnia, Viçosa, MG, v. 38, p. 109-122, 2009.

CHAVES, C. S.; GOMIDE, C. A. M.; RIBEIRO, K. G.; PACIULO, D. S. C.; LEDO, F. J. S.; COSTA, I. DEA.; CAMPANA, L. L. Forage production of elephant grass under intermittent stocking. Pesquisa Agropecuária Brasileira, Brasília, v. 48, n. 2, p. 234-240, 2013.
CLIPES, R. C.; SILVA, J. F. C.; DETMANN, E.; VASQUEZ, H. M.; SCOLFORO, L.; LOMBARDI, C. T. Avaliação de métodos de amostragem em pastagens de capim-elefante (Pennisetum purpureum, Schum) e capim-mombaça (Panicum maximum, Jacq) sob pastejo rotacionado. Arquivo Brasileiro de Medicina Veterinária e Zootecnia, Belo Horizonte, v. 57, n. 1, p. 120-127, 2005.

COOK, C. W. Symposium on nutrition of forages and pastures: collecting forage samples representative of ingested material of grazing animals for nutritional studies. Journal of Animal Science, Champaign, v. 23, $\mathrm{n}$. 1, p. 265-270, 1964.

EMPRESA BRASILEIRA DE PESQUISA AGROPECUÁRIA - EMBRAPA. Centro Nacional de Pesquisa de Solos. Sistema brasileiro de classificação de solos. 2. ed. Rio de Janeiro: EMBRAPA Solos, 2006. 306 p.

Serviço Nacional Levantamento e Classificação de Solos. Levantamento semidetalhado de solos da área do Centro Nacional de Pesquisa de Gado de Leite. Rio de Janeiro: EMBRAPA/SNLCS, 1980. 252 p. (Boletim técnico, 76).

EUCLIDES, V. P. B.; EUCLIDES FILHO, K. Uso de animais na avaliação de forrageiras. Campo Grande: Embrapa-CNPGC. 1998, 59 p. (Embrapa-CNPGC. Documentos, 74). Disponível em: <http://www.cnpgc. embrapa.br/publicacoes/doc/doc_pdf/DOC074.pdf $>$. Acesso em: 12 abr. 2012.

EUCLIDES, V. P. B.; MACEDO, M. C. M.; OLIVEIRA, M. P. Avaliação de diferentes métodos de amostragem (para se estimar o valor nutritivo de forragens) sob pastejo. Revista Brasileira de Zootecnia, Viçosa, MG, v. 21, n. 4, p. 691-702, 1992.

GAMA, T. C. M.; ZAGO, V. C. P.; NICODEMO, M. L. F.; LAURA, V. A.; VOLPE, E.; MORAIS, M. G. Composição bromatológica, digestibilidade in vitro e produção de biomassa de leguminosas forrageiras lenhosas cultivadas em solo arenoso. Revista Brasileira de Saúde e Produção Animal, Salvador, v. 10, n. 3, p. 560-572, 2009.

GOES, R. H. T. B.; MANCIO, A. B.; LANA, R. P.; VALADARES FILHO, S. C.; CECON, P. C.; QUEIROZ, A. C.; COSTA. R. M. Avaliação qualitative da pastagem de capim tanner-grass (Brachiaria arrecta), por diferentes métodos de amostragem. Revista Brasileira de Zootecnia, Viçosa, v. 32, n. 1, p. 64-69, 2003.

GOMIDE, C. A. M.; COSTA, I. A.; SOUZA, B. P.; LIMA, A. M.; PACIULLO, D. S. C.; CASTRO, C. R. T.; LÉDO, F. J. S. Valor nutritivo de genótipos de capim-elefante 
de porte baixo em resposta a estratégias de manejo. In: CONGRESSO NORDESTINO DE PRODUÇÃO ANIMAL, 5., 2008. Aracaju. Anais... Aracaju: [s.n], 2008. CD-ROM.

HOEHNE, O. E.; CLANTON, O. C.; STREETEK, C. L. Chemical changes in esophageal fistulas samples caused by salivary contamination and samples preparation. Journal of Animal Science, Champaign, v. 26, n. 3, p. 628-631, 1967.

JANUSCKIEWICZ, E. R.; MAGALHÃES, M. A.; RUGGIERI, A. C.; REIS, R. A. Massa de forragem, composição morfológica e química do capim-Tanzânia sob diferentes dias de descanso e resíduos pós-pastejo. Bioscience Journal, Uberlândia, v. 26, n. 2, p. 161-172, 2010.

LEITE, R. M. B.; QUEIROZ FILHO, J. L.; SILVA, D. S. produção e valor nutritivo do capim elefante cultivar Cameroon em diferentes idades. Agropecuária Técnica, Areia, v. 21, n. 1-2, p. 30-39, 2000.

LIRA, C. C. Comportamento de novilhas em pastagens de Pennisetum sp. sob diferentes alturas de resíduo póspastejo. 2009. Dissertação (Mestrado em Zootecnia) Universidade Federal Rural de Pernambuco, Recife.

LISTA, F. N.; SILVA, J. F. C.; VASQUEZ, H. M.; DETMANN, E.; DOMINGUES, F. N.; FEROLLA, F. S. Avaliação de métodos de amostragem qualitativa em pastagens tropicais manejadas em sistema rotacionado. Revista Brasileira de Zootecnia, Viçosa, MG, v. 36, n. 5, p. 1413-1418, 2007.

LOPES, F. C.; AROEIRA, L. J.; MALDONADOVASQUEZA, H.; VITTORI, A.; VERNEQUES, R. S. Avaliação qualitativa de dois métodos de amostragem em pastagens de capim-elefante (Pennisetum purpureum Schum.). Pasturas tropicales, Cali, v. 19, n. 3, p. 36-41, 1997.

MISLEVY, P.; MOTT, G. O.; MARTIN, F. G. Screening perennial forages by mob-grazing technique. In: INTERNATIONAL GRASSLAND CONGRESS, 14., 1981, Lexington. Proceedings... 1981, p. 516-519.

MORAES, E. H. B. K.; PAULINO, M. P.; ZERVOUDAKIS, J. T.; VALADARES FILHO, S. C.; MORAES, K. A. K. Avaliação qualitativa da pastagem diferida de Brachiaria decumbens Stapf., sob pastejo, no período da seca, por intermédio de três métodos de amostragem. Revista Brasileira de Zootecnia, Viçosa, MG, v. 34, n. 1, p. 30-35, 2005.

PACIULLO, D. S. C.; GOMIDE, J. A.; QUEIROZ, D. S.; SILVA, E. A. M. Composição química e digestibilidade in vitro de lâminas foliares e colmos de gramíneas forrageiras, em função do nível de inserção no perfilho, da idade e da estação de crescimento. Revista Brasileira de Zootecnia, Viçosa, MG, v. 30, n. 3, p. 964-974, 2001.

PALHANO, A. L.; CARVALHO, P. C. F.; DITTRICH, J. R.; MORAES, A.; SILVA, S. C.; MONTEIRO, A. L. G. Características do processo de ingestão de forragem por novilhas holandesas em pastagens de capim-mombaça Revista Brasileira de Zootecnia, Viçosa, MG, v. 36, n. 4, p. 1014-1021, 2007.

PEDROSO, C. E. S.; MEDEIROS, R. B.; SILVA, M. A.; JORNADA, J. B. J.; SAIBRO, J. C.; TEIXEIRA, J. R. F. Comportamento de ovinos em gestação e lactação sob pastejo em diferentes estádios fenológicos de azevém anual. Revista Brasileira de Zootecnia, viçosa, MG, v. 33, n. 5, p. 1340-1344, 2004.

PEREIRA, T. P.; MODESTO, E. C.; CAMPANA, L. L.; GOMIDE, C. A. M.; PACIULLO, D. S. C.; PACIULLO, D. S. C.; NEPOMUCENO, D. D.; CARVALHO, C. A. B.; MACEDO, R. O.; ALMEIDA, J. C. C. Comportamento diurno de novilhas em pastagens de clones de capimelefante anão. Revista Acadêmica de Ciências Agrárias e Ambientais, Curitiba, v. 11, n. 4, p. 383-394, 2013.

SANTANA JUNIOR, H. A.; SILVA, R. R.; CARVALHO, G. G. P.; SILVA, F. F.; COSTA, P. B.; MENDES, F. B. L.; PINHEIRO, A. A.; SANTANA, E. O. C.; ABREU FILHO, G.; TRINDADE JÚNIOR, G. Metodologias para avaliação do comportamento ingestivo de novilhas suplementadas a pasto. Semina: Ciências Agrárias, Londrina, v. 35, n. 3, p. 1475-1486, 2014.

SANTOS, G. T.; ASSIS, M. A.; GONÇALVES, G. D.; MODESTO, E. C.; CECATO, U.; JOBIM, C. C.; DAMASCENO, J. C. Determinação da digestibilidade in vitro de gramíneas do gênero Cynodon com uso de diferentes metodologias. Acta Scientiarum, Maringá, v. 22, n. 3, p. 761-764, 2000.

SILVA, A. M.; MODESTO, E. C.; LIRA, C. C.; SANTOS, M. V. F.; BRASIL, L. H. A.; DUBEUX JUNIOR, J. C. B. Caracterização do pasto e da extrusa de Novilhas Girolanda, em pastagem de Brachiaria decumbens, submetidas a diferentes taxasde lotação. Acta Scientiarum, Maringá, v. 33, n. 2, p. 115-122, 2011.

SILVA, H. W. Fatores a considerar sobre a produção de leite a pasto. Revista Brasileira de Agropecuária Sustentável (RBAS), Viçosa, v. 1, n. 2, p. 73-77, 2011.

SILVA, S. H. B.; SANTOS, M. V. F.; LIRA, M. A.; DUBEUX JUNIOR, J. C. B.; FREITAS, E. V.; FERREIRA, R. L. C. Uso de descritores morfológicos e herdabilidade de caracteres em clones de capim-elefante de porte baixo. Revista Brasileira de Zootecnia, Viçosa, MG, v. 38, n. 8, p. 1451-1459, 2009. 
SISTEMA PARA ANÁLISES ESTATÍSTICAS - SAEG. Versão 9. 1. Viçosa: Fundação Arthur Bernardes/UFV, 2007.

SOARES, J. P. G.; MARTINS, C. E.; DERESZ, F.; AROEIRA, L. J. M.; OLIVEIRA, A. D.; VERNEQUE, R. S.; BERCHIELLI, T. T. Disponibilidade e composição química do capim-elefante (Pennisetum purpureum schum.) em pastejo sob dois níveis de nitrogênio. ARS Veterinária, Jaboticabal, v. 18, n. 3, p. 248-257, 2002.

SUN, X. Z.; WAGHORN, G. C.; CLARK, H. Cultivar and age of regrowth effects on physical, chemical and in sacco degradation kinetics of vegetative perennial ryegrass (Lolium perenne L.). Animal Feed Science and Technology, Amsterdam, v. 155, n. 2, p. 172-185, 2010.

THARMARAJ, J.; WALES, W. J.; CHAPMAN, D. F.; EGAN, A. R. Defoliation pattern, foraging behaviour and diet selection by lactating dairy cows in response to sward height and herbage allowance of a ryegrassdominated pasture. Grass and Forage Science, Oxford, v. 58, n. 3 , p. $225-238,2003$.

TILLEY, J. M. A.; TERRY, R. A. A two-stage technicique for the in vitro digestion of forage digestibility. Journal of Bristh Grassland Society, Kenilworth, v. 18, n. 2, p. 104-111, 1963.

TREVISAN, N. B.; QUADROS, F. L. F.; CORADINI, F. S.; BANDINELLI, D. G.; MARTINS, C. E. N.; SIMÕES, L. F. C.; MAIXNER, A. R.; PIRES, D. R. F. Comportamento ingestivo de novilhos de corte em pastagem de aveia preta e azevém com níveis distintos de folhas verdes. Ciência Rural, Santa Maria, v. 34, n. 5, p. 1543-1548, 2004.
TRINDADE, J. K.; SILVA, S. C.; SOUZA JUNIOR, S. J.; GIACOMINI, A. A.; ZEFERINO, C. V. G.; CARVALHO, P. C. F. Composição morfológica da forragem consumida por bovinos de corte durante o rebaixamento do capimmarandu submetido à estratégia de pastejo rotativo. Pesquisa Agropecuária Brasileira, Brasília, v. 42, n. 6, p. 883-890, 2007.

VAN SOEST, P. J. Nutrition ecology of the ruminant. Ithaca: Comstock Publishing Associates, 1994. 476 p.

VAN SOEST, P. J.; ROBERTSON, J. B.; LEWIS, B. A. Methods for dietary fiber; neutral detergent fiber, and non starch polysaccharides in relation to animal nutrition. Journal of Dairy Science, Madison, v. 74, n. 10, p. 35833597, 1991.

VEIGA, J. B.; MOTT, G. O.; RODRIGUES, I. R. A.; OCUMPAUGH, W. O. Capim elefante anão sob pastejo. I. Produção de forragem. Pesquisa Agropecuária Brasileira, Brasília, v. 20, n. 8, p. 929-936, 1985.

ZANINETTI, R. A.; REIS, R. A.; BERTIPAGLIA, L. M.; MELO, G. M.; OLIVEIRA, A. P.; BERCHIELLI, T. T. Degradação in situ da matéria seca e da fração fibrosa do capim-marandu obtido por diferentes métodos de amostragem, no período seco do ano. Ciência e Agrotecnologia, Lavras, v. 34, n. 3, p. 603-609, 2010. 